Zeitschrift für Kristallographie, Bd. 124, S. 375-377 (1967)

\title{
Refinement of the crystal structure of arsenic tribromide
}

By A. K. SINGH * and S. SwaminathaN

Department of Physics, Indian Institute of Technology

Madras, India

(Received August 10, 1965 and in revised form June 20, 1966)

\begin{abstract}
Auszug
Bericht über eine Verfeinerung der Kristallstruktur von $\mathrm{AsBr}_{3}$ (bis zu $R=0.143$ ).
\end{abstract}

\section{Abstract}

Refinement of the crystal structure of arsenic tribromide is reported.

A single crystal of arsenic tribromide was obtained by crystallizing the specimen in a sealed thin-walled capillary tube ${ }^{1}$ (radius $0.31 \mathrm{~mm}$ ). The intensity data were collected using equi-inclination Weissenberg technique. The intensities were measured visually and corrected for absorption and Lorentz-polarisation factors.

The coordinates reported by Singh and Swaminathan ${ }^{2}$ gave an $R$ factor of 0.26 . Further refinement by the method of least squares was attempted on the Elliott $803 \mathrm{~B}$ computer. The analytical expression of FoRsyTh and WeLLS ${ }^{3}$ was used for atomic scattering factors. Only individual isotropic temperature factors were used. After four cycles of refinement the $R$ factor dropped to 0.143 . No attempt was made to apply anisotropic temperature factors.

* The present address: Material Sciences Division, National Aeronautical Laboratory, Bangalore-17, India.

1 A. K. Srngh and S. Ramaseshan, A low temperature attachment to the Weissenberg goniometer. Proc. Indian Acad. Sci. 60 (1964) 20-24.

${ }^{2}$ A. K. Singh and S. Swaminathan, The crystal and molecular structure of arsenic tribromide at $-10^{\circ} \mathrm{C}$. Curr. Sci. 33 (1964) 429-430.

${ }^{3}$ J. B. Forsyth and M. M. Wells, On an analytic approximation to the atomic scattering factor. Acta Crystallogr. 12 (1959) 412-415. 
The observed and calculated structure amplitudes are listed in Table 1. The final positional and thermal parameters together with those reported by BraekKeN ${ }^{4}$ and Trotter $^{5}$ are given in Table 2.

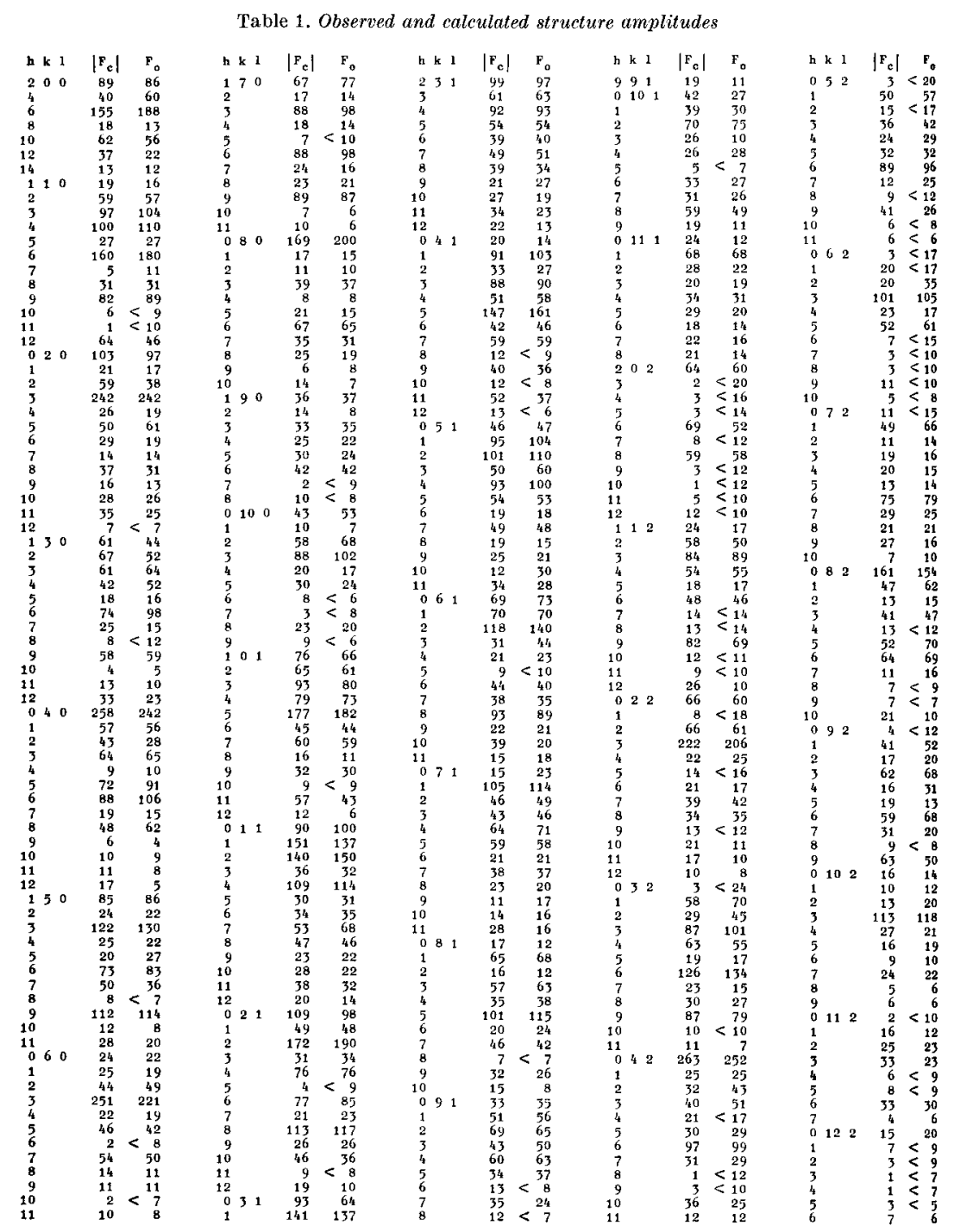

${ }^{4}$ H. Brakkken, Die Kristallstruktur von Arsen- und Antimontribromid. Kgl. Norske Videnskab Selskab 8 (1935) Nr. 10.

5 J. Trotter, The crystal structure of arsenic tribromide. Z. Kristallogr. 122 (1965) 230-236. 
Table 2. The final positional and thermal parameters

\begin{tabular}{l|c|l|l|l|l|l|l|c}
\hline Atom & Author & $x$ & $y$ & $z$ & $\sigma(x)$ & $\sigma(y)$ & $\sigma(z)$ & $B$ \\
\hline \multirow{2}{*}{$A \mathrm{~s}$} & $B$ & 0.300 & 0.215 & 0.000 & - & - & - & - \\
& $T$ & 0.3030 & 0.2118 & 0.0004 & 0.0013 & 0.0008 & 0.0059 & $1.16 \AA^{2}$ \\
& $A$ & 0.3047 & 0.2129 & 0.0085 & 0.0007 & 0.0007 & 0.0050 & 3.44 \\
$\operatorname{Br}(1)$ & $B$ & 0.307 & 0.377 & -0.262 & - & - & - & - \\
& $T$ & 0.3010 & 0.3794 & -0.2824 & 0.0010 & 0.0007 & 0.0045 & 1.49 \\
& $A$ & 0.3022 & 0.3799 & -0.2643 & 0.0008 & 0.0007 & 0.0040 & 2.67 \\
$\operatorname{Br}(2)$ & $B$ & 0.133 & 0.123 & -0.262 & - & - & - & - \\
& $T$ & 0.1380 & 0.1198 & -0.2752 & 0.0010 & 0.0008 & 0.0053 & 1.79 \\
& $A$ & 0.1387 & 0.1198 & -0.2604 & 0.0008 & 0.0007 & 0.0060 & 3.00 \\
$\operatorname{Br}(3)$ & $B$ & 0.482 & 0.123 & -0.250 & - & - & - & - \\
& $T$ & 0.4825 & 0.1307 & -0.2504 & 0.0010 & 0.0008 & 0.0071 & 1.96 \\
& $A$ & 0.4831 & 0.1318 & -0.2611 & 0.0008 & 0.0008 & 0.0062 & 2.97
\end{tabular}

The present coordinates and those reported by TrotTer ${ }^{5}$ have been transformed to the set of axes chosen by BRAEKKEN ${ }^{4}$.

The axes of coordinates chosen by the different authors are related by

$$
\begin{aligned}
& a_{B}=b_{T}=-b_{A} \\
& b_{B}=-c_{T}=a_{A} \\
& c_{B}=-a_{T}=c_{A}
\end{aligned}
$$

and the coordinates by

$$
\begin{aligned}
& x_{B}=y_{T}=\frac{3}{4}-y_{A} \\
& y_{B}=\frac{1}{2}-z_{T}=-\frac{1}{4}+x_{A} \\
& z_{B}=-x_{T}=-\frac{1}{4}+z_{A}
\end{aligned}
$$

$B-$ Brakk ken $^{4}, T-$ Trotter $^{5}$ and $A-$ the present author

The authors are thankful to Professor S. Ramaseshan for his continued interest and encouragement and to Prof. B. R. PAI of the Presidency College, Madras, for supplying the specimen of arsenic tribromide. 